\title{
The Risk of Tuberculosis among Populations Living in Slum Settings: a Systematic Review and Meta-analysis
}

\author{
Ekaterina Noykhovich (D) Sangeeta Mookherji • \\ Amira Roess
}

Published online: 19 October 2018

(C) The New York Academy of Medicine 2018

\begin{abstract}
According to the WHO, half of the 10.4 million incident cases of TB in 2016 came from five countries where $20-50 \%$ of the urban population live in slums. Crowded living conditions and limited access to healthcare further contribute to the burden of $\mathrm{TB}$ in urban slums. This article aims to assess the odds of the burden of TB in urban slums through a systematic review and meta-analysis. Four electronic databases were searched for studies published between 1993 and 2017, with TB defined as at least one sputum smearpositive. The review followed the PRISMA protocol and information was extracted from articles for a fulltext review to determine eligibility. Odds ratios were calculated for studies reporting sputum smear-positive TB cases in slum settings with national incidence as a comparison. Summary estimates were calculated using the random effects model $(95 \% \mathrm{CI})$ and publication bias was assessed through funnel plot analysis. A quality assessment of included articles was also conducted. This meta-analysis was conducted across three categories: (1) across all 22 studies, (2) studies utilizing Active Case Finding, and (3) studies conducted in a high TB-HIV setting. The odds of sputum smear-positive TB were significantly higher across all three categories of analysis. Compared with national TB incidence rates, the combined odds ratio of smear-positive TB within slums was $2.96(2.84,3.09 ; p<0.01)$. The combined odds
\end{abstract}

E. Noykhovich $(\bowtie) \cdot$ S. Mookherji $\cdot$ A. Roess

Department of Global Health, Milken Institute School of Public Health, George Washington University, 950 New Hampshire Ave. NW, Washington, DC 20052, USA

e-mail: Katya.Noykhovich@gmail.com ratio for smear-positive TB with active case finding across 15 studies was 2.85 (2.71, 2.99; $p<0.01)$. Among the 11 studies that reported incidence of smear-positive TB with prevalent TB-HIV coinfection in the community, the combined odds ratio for slum residents with the random effects model was 2.48 $(2.34,2.63 ; p<0.01)$. Using Egger's funnel plot, publication bias was not detected within the three categories of analysis. The findings of this analysis indicate that the odds of developing TB are almost five times as great in urban slums. Reaching the most vulnerable and often overlooked groups in slums is crucial to achieving the SDGs and End TB Strategy by 2035.

Keywords Urban poor $\cdot$ Slums $\cdot$ Tuberculosis $\cdot$ Key populations $\cdot$ End TB strategy

\section{Introduction}

In 2016, an estimated 10.4 million incident cases of TB occurred, with $56 \%$ of these new cases in only five countries: India, Indonesia, China, the Philippines and Pakistan [1], which are between 33 and $60 \%$ urbanized [2]. Due to high population density, crowded living and working conditions, and lifestyle changes associated with urban living, the rate of TB tends to be higher in urban areas compared to rural areas [3, 4]. Thirty-five countries (out of 93) with a high proportion of urban populations living in slums also are characterized by a high incidence of TB (Figs. 1 and 2) [1, 5]. 


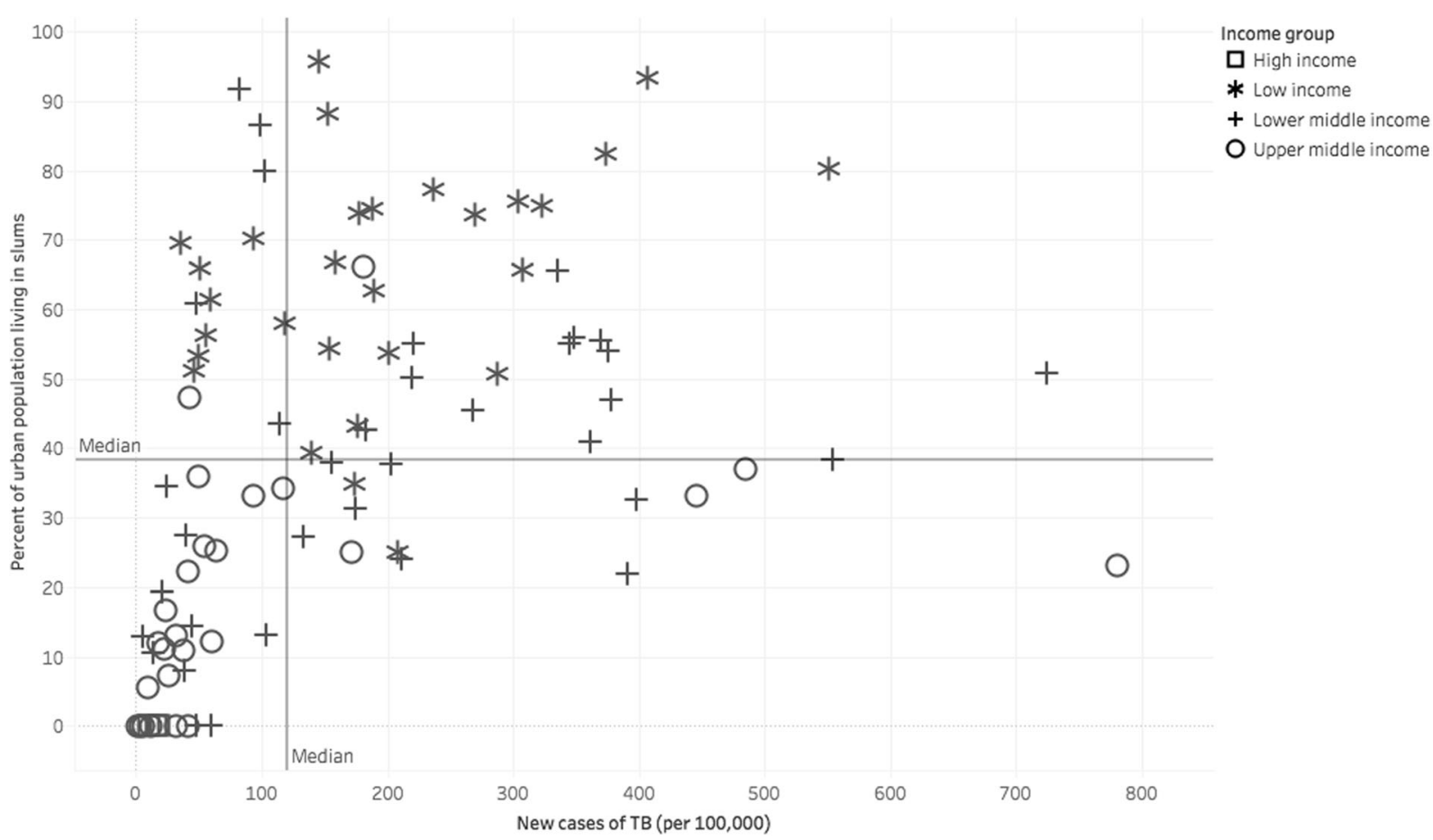

Fig. 1 New cases of TB (per 100,000) vs. percent of urban population living in slums. Data source; WHO Global Health Repository and SDG Indicators Database (2016). Figure created with Tableau.

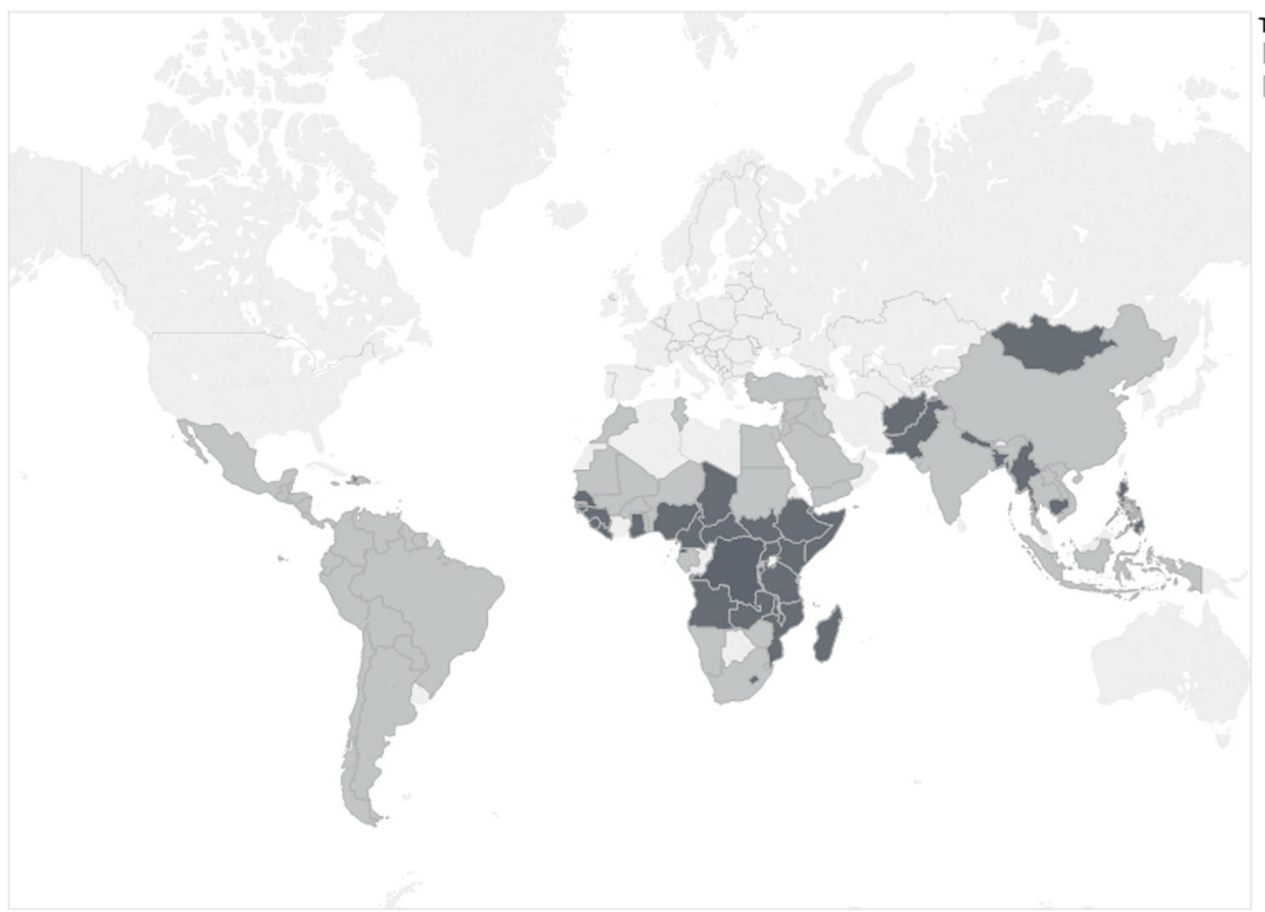

TB incidence and proportion in slums

Below median

Fig. 2 Countries with the highest TB incidence rates and proportion of urban population living slums as measured by above/below median. Data source: WHO Global Health Repository and SDG Indicators Database (2016). Figure created with Tableau. 
Within urban areas, slum settlements exhibit TBfacilitating qualities to an even greater degree. The United Nations defines a "slum household" as one in which the inhabitants suffer one or more of the following "household deprivations": (1) lack of access to improved water source, (2) lack of access to improved sanitation facilities, (3) lack of sufficient living area, (4) lack of housing durability, and (5) lack of security of tenure [6]. Slum communities are well-known as living quarters for migrants, displaced persons, and other groups that may not have access to national health programs [6-8]; in addition, slums are breeding grounds for infectious diseases, including tuberculosis, which spread easily in highly concentrated populations [9-11]. The 5 top-contributing countries to the continued global TB burden have between 25 and $50 \%$ of their urban populations living in slum conditions [2].

In addition to environmental characteristics that facilitate the spread of TB, urban slum residents also have access to a highly diverse set of healthcare providers that pose numerous programmatic challenges for TB control. Most importantly, private health care providers are the most common first point of contact for urban residents, even the urban poor who live in slum areas, despite the high out-of-pocket costs [12-14]. Persons with presumptive TB are often not diagnosed or treated according to international standards, and do not appear in national TB reports. In recognition of this, the Stop TB Partnership incorporated Engaging All Providers in the Global Plan to Stop TB 2004-2008, with Public-Private Mix DOTS (PPM-DOTS) as the primary strategy to strengthen this weak link; PPM-DOTS was shown to be an effective approach over the following decade [13, 15, 16].

Recently, the WHO announced the End TB Strategy to "End the global TB epidemic" to reduce TB deaths by $95 \%$ and TB incidence by $90 \%$, both by 2035 [1]. The principles of the End TB Strategy address government accountability, building a strong coalition with civil society and communities, protecting and promoting human rights, and adapting the strategy at country level with global collaboration [17]. The End TB Strategy focuses on (1) integrated, patient-centered care and prevention with a focus on diagnosis and treatment, and preventative action for persons at high risk; (2) policy and supportive systems, including political commitment, universal health coverage, and social protection; and (3) intensified research and innovation in strategies, interventions and tools, as well as research to optimize implementation [17].
In line with this strategy, the Sustainable Development Goals also address the TB epidemic and improving the conditions for slum populations. Specifically, Goal 3.3 aims to end the epidemics of AIDS, TB, malaria, and those of neglected tropical diseases, as well as to combat hepatitis, water-borne diseases, and other communicable diseases; Goal 11.1 aims to ensure access for all to adequate, safe, and affordable housing and basic services and upgrade slums, both by 2030 [5].

The strategy of engaging all providers continues to be an important element of the End TB Strategy (Pillar 2.B.) [17]; however, although "people who live in urban slums" [18] is identified as a key population for targeting, The Data for Action for Tuberculosis: Key, Vulnerable and Underserved Populations report [19] fails to specify slum residents, or even urban populations, as a key population, although a subsequently published Key Population Brief [20] and the Global Report on Urban Health [21] do focus on urban populations. This research reviews existing literature to estimate the increased odds of TB faced by slum residents, in the hopes that slum-specific strategies for ending TB will be prioritized and developed.

\section{Methods}

This is a systematic literature review and meta-analysis to assess the burden of TB among populations living in slum settings.

\section{Search Strategy}

This review follows the research methods and reporting guidelines as described in the PRISMA statement and in the Cochrane Handbook for systematic reviews [22]. Four electronic databases were searched: CINAHL, MEDLINE (OvidSP), Pubmed, and SCOPUS. Studies that collected data or were published prior to 1993 were excluded, as changes to TB strategies are assumed to have taken effect after the WHO announced TB as a global emergency and endorsed DOTS in 1993. The population of interest for this review were individuals living in slum settings. The outcome of interest was tuberculosis, defined as at least one positive sputum smear for TB. Specific search terms included: slum, shanty-town, favela, kijiji, johpadpatti, gecekondu, aashiwa'I, barriada, kampong, mudukku, and periurban and tuberculosis [8]. The search strategy included 
"tuberculosis" and the corresponding slum terms with an "AND" operator; for example, tuberculosis AND favela. References of the included articles were searched to ensure a comprehensive review.

\section{Inclusion/Exclusion Criteria}

Only studies published in English were included. A threestage process was employed to select articles for the systematic review and meta-analysis (Fig. 3). Stage one excluded duplicate articles among the predefined databases based on title alone and removed duplicate articles. Stage two excluded articles through abstract review and excluded studies which collected data prior to 1993, opinion pieces, essays, the objective of the study was not directly related to TB, the study was not in a slum setting, or if the study's primary focus was on describing molecular techniques, vaccine development or zoonotic TB.

Stage three consisted of a full-text review for relevance to the study objectives and extracted key information from each article: study design, duration, setting, sampling, participant/population information, TB case definition and diagnostic methodology, and outcomes (incidence, prevalence). Articles that did not provide a clear description of study design and methods, used qualitative methods only, collected data prior to 1993 , or conducted financial analyses among other reasons (Fig. 3) were excluded at Stage three. Further review of extracted articles produced a more refined list of included articles for analysis based on the above information, with

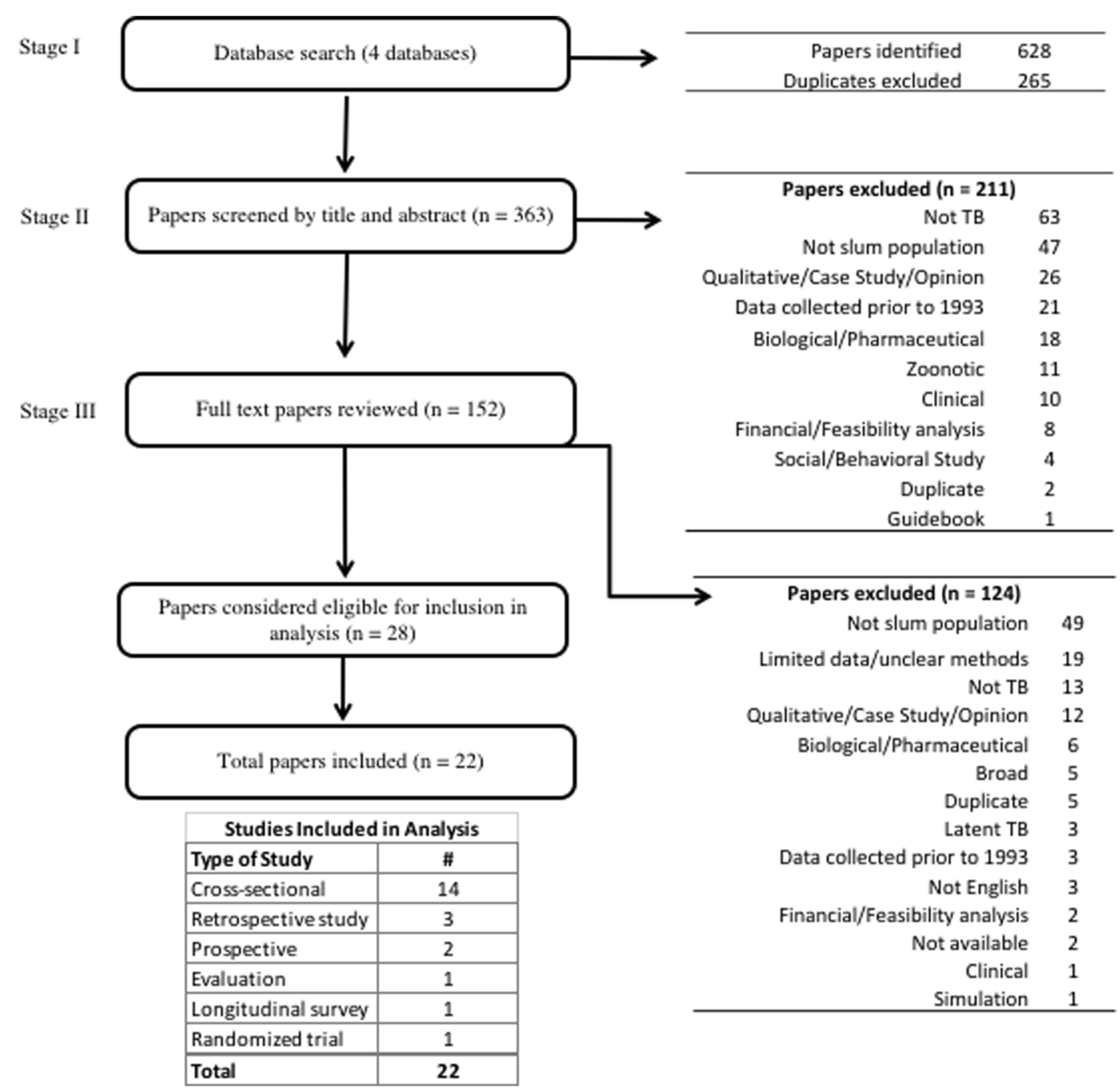

Fig. 3 Search strategy and exclusion criteria 
specific focus on study design and diagnostic methodology of a TB case. ProQuest Refworks and MS Excel were used to identify duplicates, and MS Excel was used to record and maintain information extracted from each study through the review stages. Articles at all three stages were reviewed and selected by one reviewer (EN), but the methodology of each stage was confirmed with the other authors (SM, AR).

\section{Quality Assessment of Selected Studies}

A series of questions were adapted to assess the quality of the 22 included studies reporting on tuberculosis among slum populations and assessed the independence of the study, robustness of methodology, definition of a tuberculosis case, robustness of data analysis, and reporting of confounding factors [23, 24]. Responses to these questions were recorded and maintained in an MS Excel spreadsheet.

\section{Outcomes and Definitions}

The definition of a TB case was based on at least one positive sputum smear result for TB. The comparison group in this analysis was the national incidence rate of smear-positive TB as within-study comparison groups were not similar enough across all studies to serve as a matched comparison group. To determine if diagnostic methods or population groups have an effect on the rate of TB among slum settings versus the national rate, analyses were grouped by:

1) Smear-positive TB cases

2) Active case finding as method of TB case finding

3) TB-HIV coinfection reported in study population
Akhtar, S. et al .2007

Banu, S. et al. 2013

Fatima, R. et al. 2014

Fatima, R. et al. 2016

Guwatudde, D. et al. 2003

Hoseinpoor, R. et al. 2017

Khanal, S. et al. 2016

Koenig, S.P. et al. 2015

Lorent, N.et al. 2014

Miller, A.C. et al. 2010

Ogbudebe, C.L. et al. 2015

Prasad, B.M. et al. 2016

Sekandi, J.N.et al. 2009

shrivastava, S.R. et al. 2013

Wood, R. et al. 2007

Cavalcante, S.C. et al. 2007

Lawn.S.D. et al. 2006

Mendes, JM et al. 2007

Reif, L.K.et al. 2016

Saunders, MJ. et al. 2017

shrivastava, S.R. et al. 2013b (TB-HIV)

Tupasi, T.E.et al. 2000

Overall $(95 \% \mathrm{CI})$

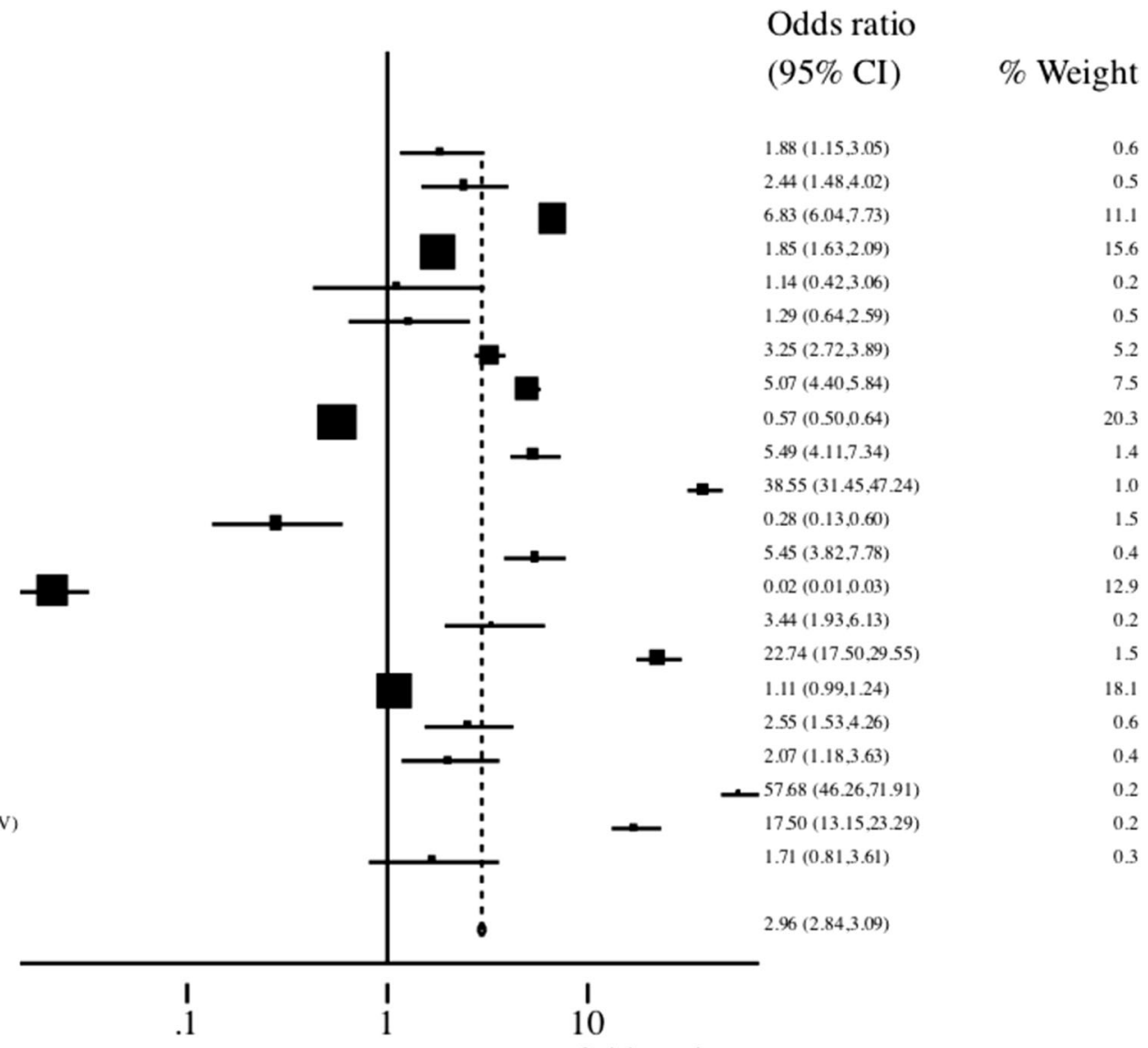

Odds ratio

Fig. 4 Forest plot of TB incidence in studies reporting sputum smear-positive TB in slum settings $(n=22)$ 
Meta-analysis

To calculate an odds ratio, the number of new smearpositive TB cases reported by each study was used as the numerator, and the number of people within the study sample (or slum population screened by the study when study sample number was not available) was used as the denominator; the comparison group was the national TB incidence from the WHO Global TB Report [25].

This meta-analysis followed the guidelines of previous meta-analysis recommendations for Stata [26]. TB incidence rates were pooled and odds ratios were calculated using the random effects model. The random effects model (DerSimonian and Laird) was chosen to represent the combined summary estimate across studies because it assumes that the studies differ to the extent that they could impact the risk estimate, whereas the fixed effect model assumes that the effect size is the same in all study populations and therefore was not appropriate for this analysis [27]. All of the studies included in the summary estimate calculations are not equal in terms of sample characteristics - they vary slightly in TB diagnosis (some use a combination of sputum smear and bacterial culture, others use sputum smear only), the age groups vary slightly across studies, and the male-female ratio is different throughout studies. Therefore, the random effects models were preferred for this analysis and conducted using Stata 13.1.

The random effects models were also tested for asymmetry which could stem from publication bias, location bias, reporting bias, poor methodological quality, true heterogeneity, artefactual, or from chance alone [28]. The Egger test for funnel plot symmetry was employed based upon recommendations and that it "corresponds to a linear regression of the log odds ratio on its standard error, weighted by the inverse of the variance of the log odds ratio" $[22,28]$. Funnel plots were generated by plotting the log odds ratio and its standard error, as a measure of study size [26, 28, 29]. Although funnel plot tests are limited by low power and

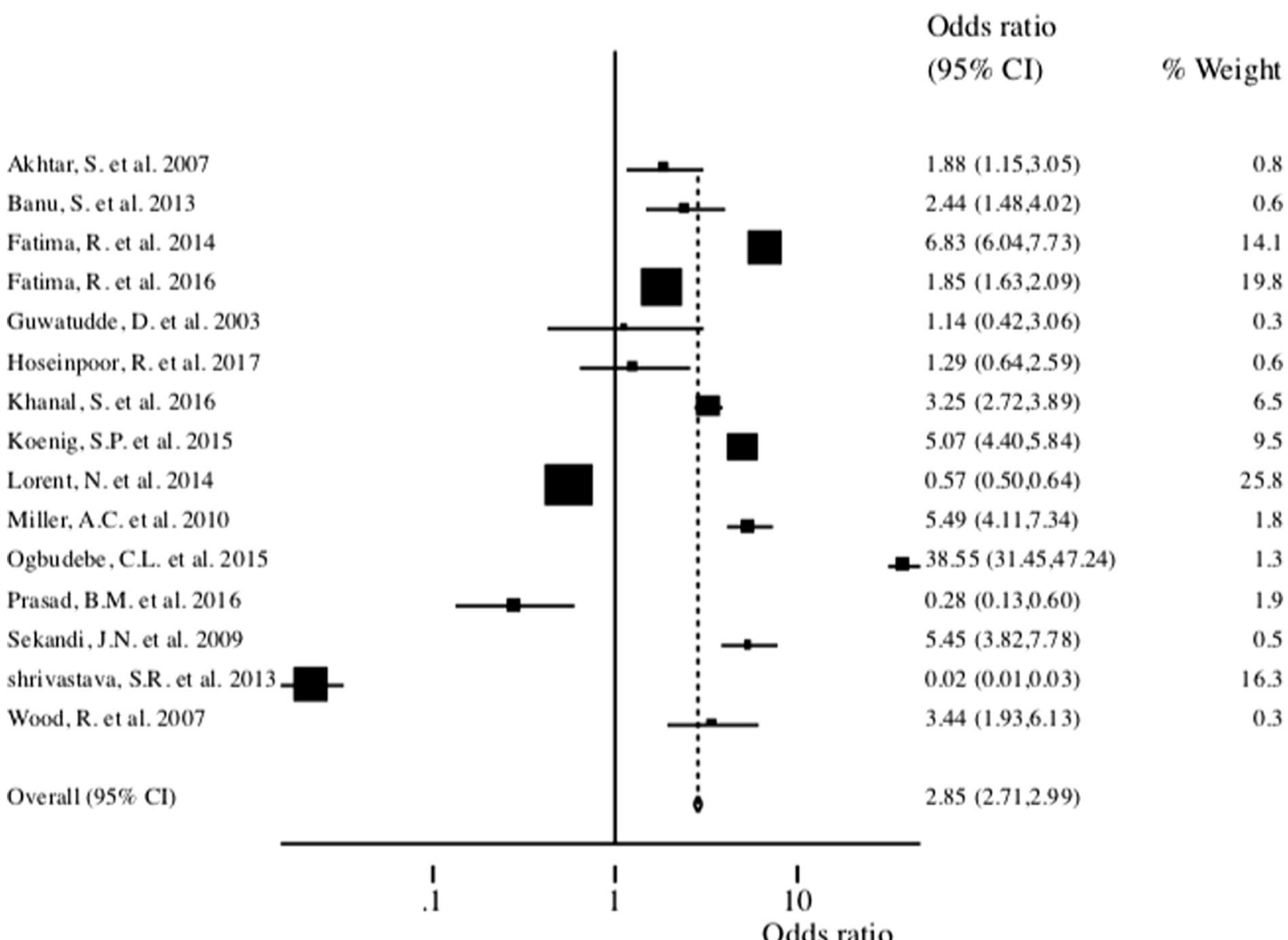

Fig. 5 Forest plot of TB incidence in studies reporting use of active case finding for TB in slum settings $(n=15)$ 
any large $p$ values should be interpreted with caution, this is still a standard test for bias [28].

\section{Results}

After a full-text review of 152 articles, 124 were excluded based on the identified criteria, with 28 papers considered eligible for the analysis (Fig. 3). Among the 28 papers reviewed, 6 were deemed ineligible based on duplicated study populations and limited data availability. Of the 22 included articles, there were 14 crosssectional studies, three retrospective surveys, two prospective studies, one evaluation, one longitudinal study, and one randomized trial.

Three studies were carried out in India, three in Brazil, two in South Africa, three in Pakistan, two in Haiti, two in Uganda, and one each in Bangladesh, Cambodia, Iran, Nepal, Nigeria, Peru, and the Philippines. All of these countries, excluding Iran, are or have been high-burden countries in the twenty-first century.
All studies were carried out in slum settings as stated in the articles-slums, peri-urban neighborhoods/townships, and urban poor settlements [30-32].

All 22 studies used sputum smears as at least one form of TB diagnosis. Active case finding for TB was reported in 15 of the 22 studies. No studies reported an incentive for reporting TB cases, and there was no reported epidemic of TB in the study populations, although the studies in Haiti were conducted after the major 2011 Haiti earthquake. Eleven out of 22 studies reported TB-HIV coinfection within the study population. Two studies reported drug resistance to at least one drug within the study population [33, 34].

The results from each random effects model are shown in Figs. 4, 5 and 6 as forest plots; these graphs show the odds ratio estimates and $95 \%$ confidence interval from each study included in the analysis, the weight based on original study sample size, and the overall odds ratio estimate and 95\% confidence interval across all studies.
Guwatudde, D. et al. 2003

Khanal, S. et al. 2016

Koenig, S.P. et al. 2015

Lorent, N. et al. 2014

Ogbudebe, C.L. et al. 2015

Sekandi, J.N. et al. 2009

Wood, R. et al. 2007

Lawn, S.D. et al. 2006

Mendes, JM et al. 2007

Reif, L.K.et al. 2016

shrivastava, S.R. et al. 2013b (TB-HIV)

Overall $(95 \% \mathrm{CI})$
Odds ratio

(95\% CI)

$\%$ Weight

$1.14(0.42,3.06)$

0.4

$3.25(2.72,3.89)$

9.5

13.8

37.6

1.9

0.7

0.4

$3.44(1.93,6.13)$

33.5

$1.11(0.99,1.24)$

1.0

$2.07(1.18,3.63)$

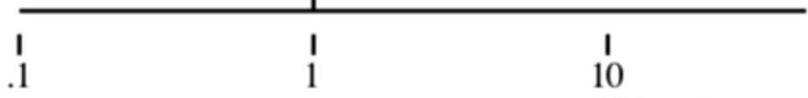

Odds ratio

Fig. 6 Forest plot of TB incidence in studies reporting prevalence of HIV within slum settings $(n=11)$ 
Fig. 7 a Egger test to assess publication bias - all studies defining TB as sputum smearpositive. b Egger test to assess publication bias-all studies defining TB as sputum smearpositive and using active case finding. c Egger test to assess publication bias - all studies defining TB as sputum smearpositive and reporting TB-HIV coinfection within the study population a Egger's publication bias plot

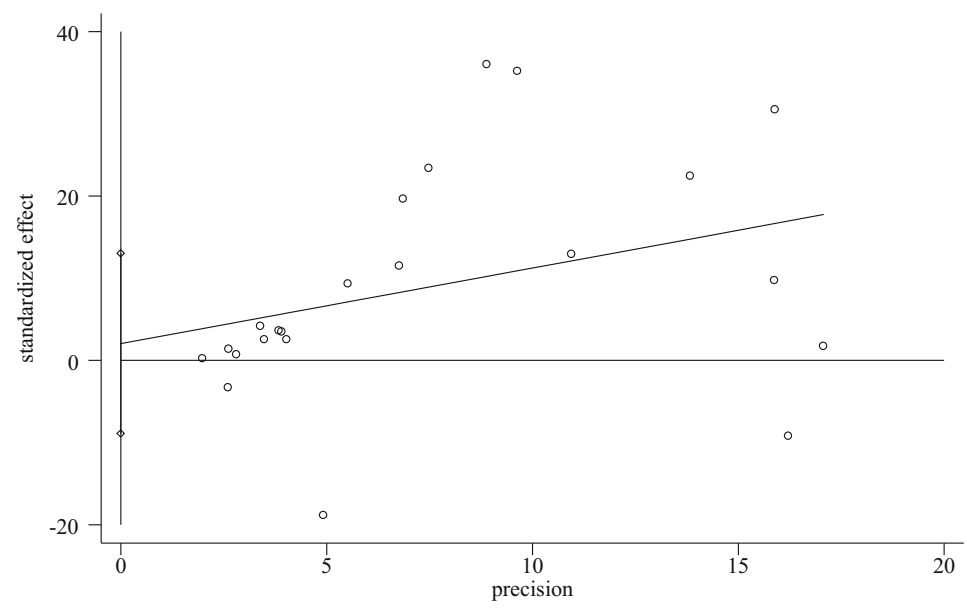

b Egger's publication bias plot

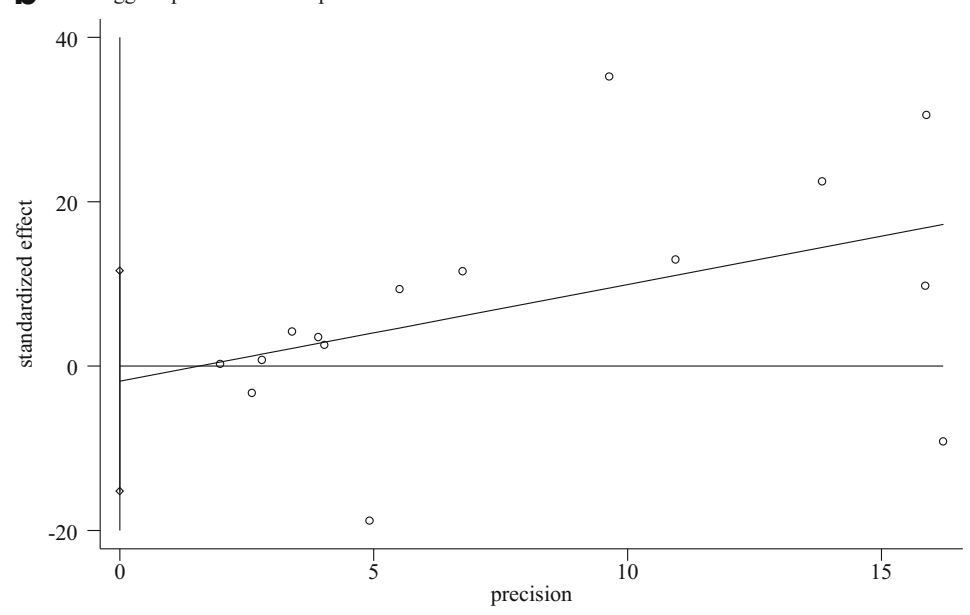

C Egger's publication bias plot

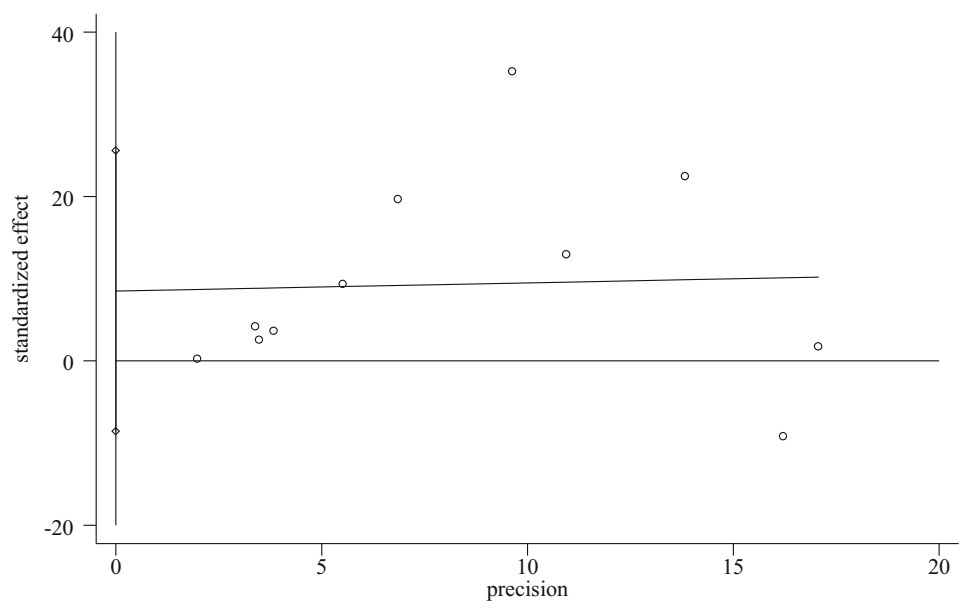


Among the 22 studies that reported incidence of smear-positive TB cases, the combined odds ratio for slum residents with the random effects model was 2.96 $(2.84,3.09 ; p<0.01)$ (Fig. 4). Publication bias was not detected using Egger's funnel plot for all 22 smearpositive TB studies, which shows a symmetric pattern (P for bias 0.702 (Fig. 7a). Among the 15 studies that reported incidence of smear-positive TB cases through active case finding, the combined odds ratio for slum residents with the random effects model was 2.85 (2.71, 2.99; $p<0.01$ ) (Fig. 5). Publication bias was not detected using Egger's funnel plot for smear-positive TB and active case finding studies which shows a symmetric pattern (P for bias 0.771) (Fig. 7b). Among the 11 studies that reported incidence of smear-positive TB with prevalent TB-HIV coinfection in the community, the combined odds ratio for slum residents with the random effects model was $2.48(2.34,2.63 ; p<0.01)$ (Fig. 6). Publication bias was not detected using Egger's funnel plot, which shows a symmetric pattern (P for bias 0.289) (Fig. 7c). However, funnel plots are limited in their low power and large $p$ values should be interpreted with caution [28].

The results of the quality assessment indicate that the majority of studies (17 of 22) reported no conflict of interest, with an undeclared conflict of interest in five studies (Fig. 8). Almost all studies clearly described methods and reported sampling procedures implemented (21 of 22), with all 22 studies clearly defining TB cases (Table 1). All but two studies described limitations to some extent; one study reported on the potential confounding role of underlying lung disease, and five studies described potential factors that may have affected result leading to underestimated incidence of TB in the study population.

The results from this meta-analysis indicate an increased likelihood for an individual to develop TB in a slum setting when compared to their country as a whole, ranging from three to five times greater likelihood, depending on context and TB control program strategies. The odds of sputum smear-positive TB, with active case finding, were significantly higher in slum settings than the national-level odds. Sputum smear-positive TB incidence in high-HIV burden countries was also significantly higher in slum settings, compared to national incidence rates.

\section{Discussion}

The findings from this meta-analysis indicate an increased likelihood for an individual to develop TB in a slum setting when compared to their country as a whole, ranging from three to five times greater likelihood, depending on context and TB control program strategies. The odds of sputum smear-positive TB were significantly higher across all three areas of analysis. The results of this meta-analysis support the reported challenges and recommendations stated in previous studies [54-59].

Governments and non-governmental organizations continue to face challenges for controlling TB in slum settings, and several studies have made recommendations to address key issues. One barrier to TB control in slums is government recognition of slums as areas that have rights to publicly provided services, including health services, as well as water and sanitation, electricity, etc. Lack of knowledge and access to TB diagnosis and treatment among slum residents, in addition to treatment non-adherence, delay in diagnosis, lack of pills, and lack of money, are contributing factors that must be addressed to reduce the burden of TB [60, 61].

Another barrier for effective TB control in slum settings is the role the private sector plays. Coupled with the ongoing challenge of limited information about the health status of slum communities [8], TB control

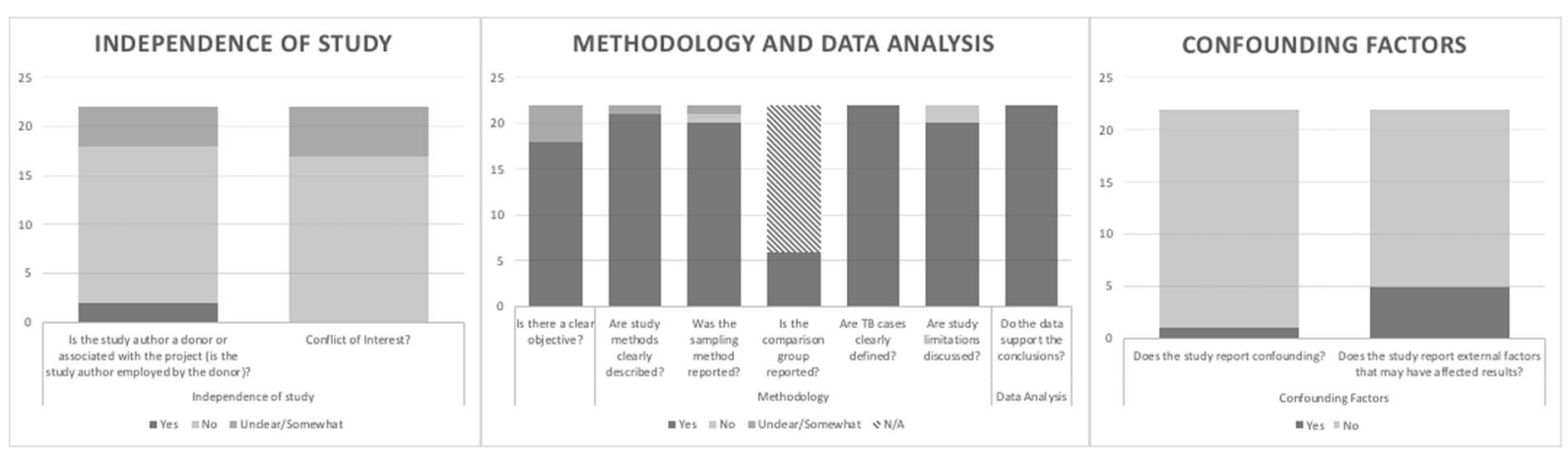

Fig. 8 Quality assessment of 22 included studies for analysis 


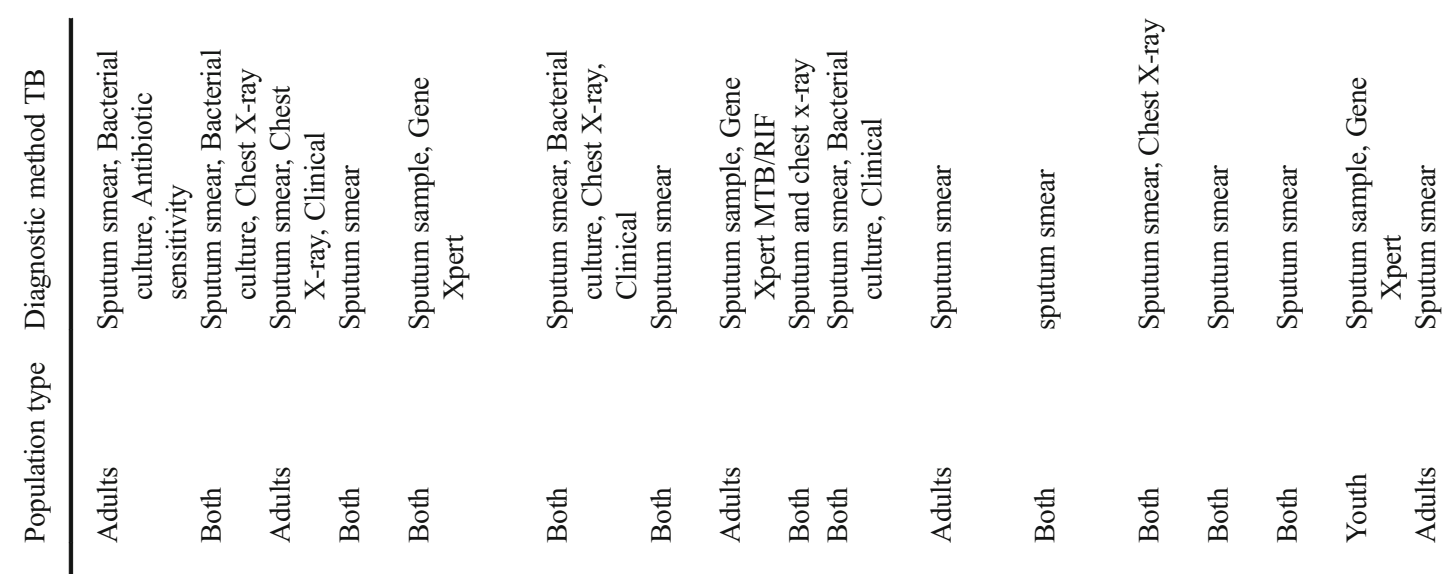

咅

$\stackrel{m}{3}$

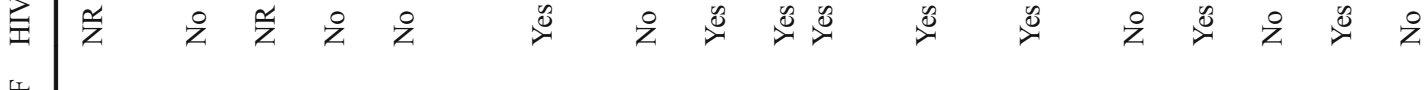

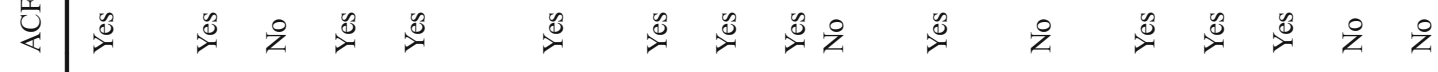

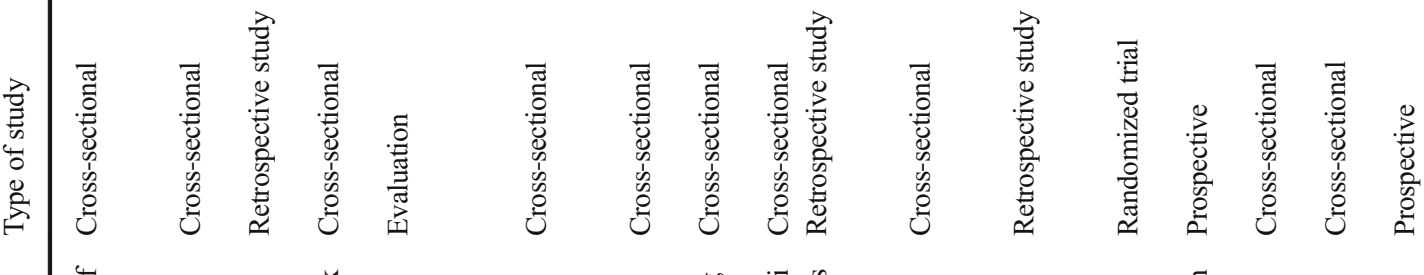

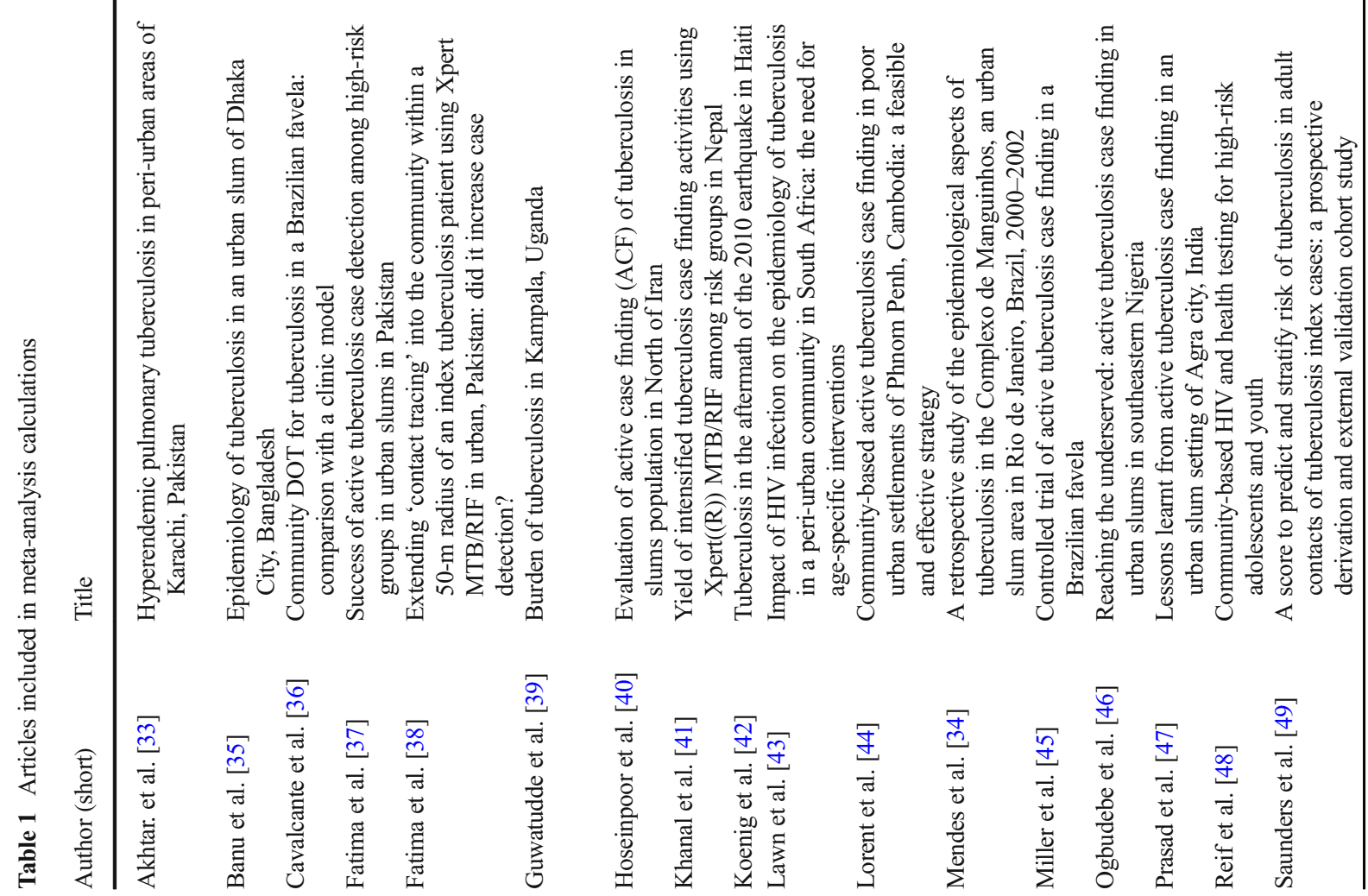




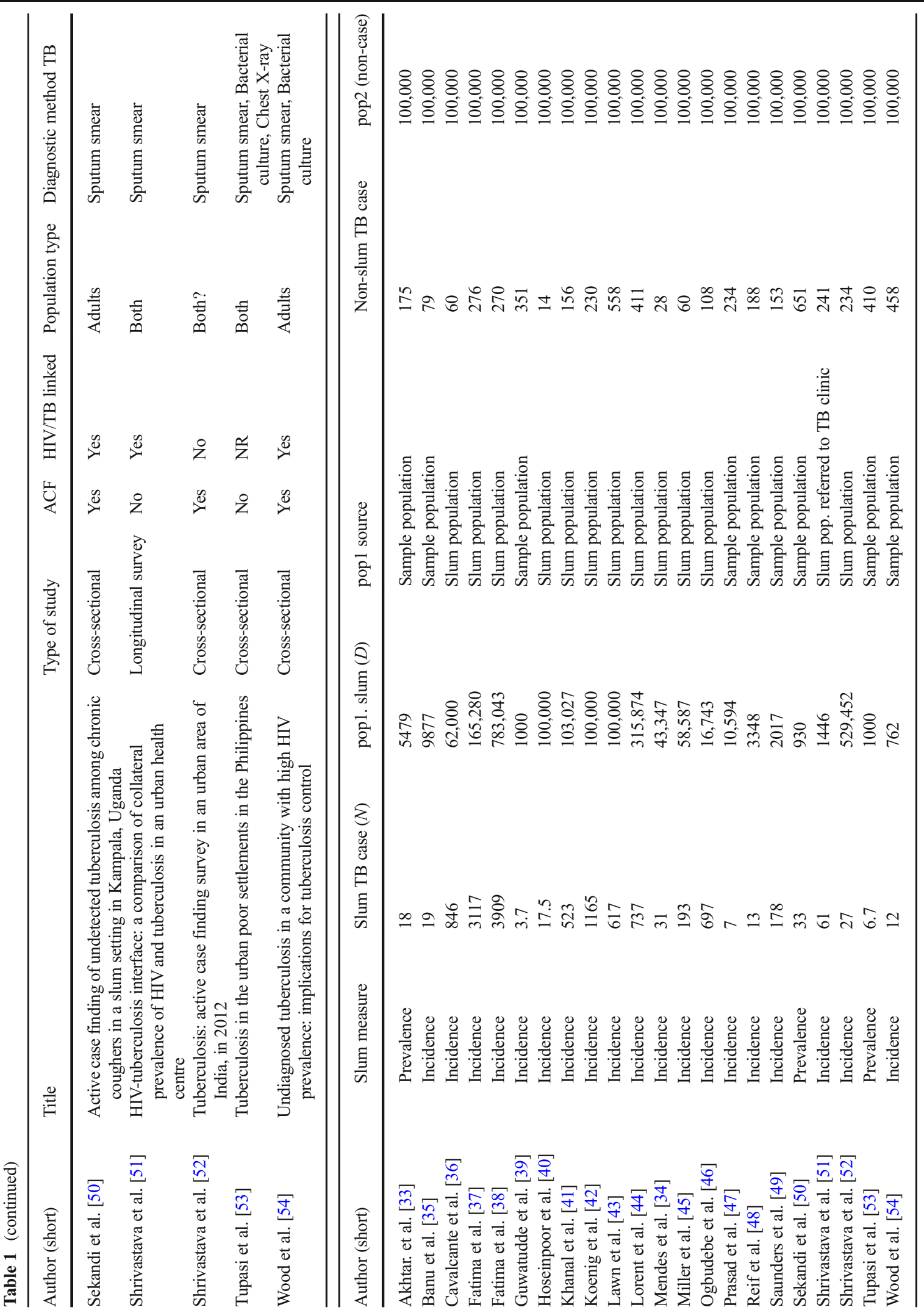


programs need slum-specific innovations to effectively address the information gap and to identify and treat all people affected by TB. Active case finding and innovative screening and treatment programs building on the PPM-DOTS approach should be explored in countries with a high proportion of the urban population living slums, as recommended in the Stop TB Partnership's Key Population Brief: urban populations [20].

A global push towards regional collaboration and national recognition of the rights of people living in slum settings are a necessary step to ending the burden of TB. While the Key Populations Brief: Urban Populations outlines actions to address poor urban residents, the End TB Strategy does not include this group in the report, and the lack of coherence between the Global Strategy and the specific recommendations for key populations increases the risk that urban slum populations will continue to be overlooked in terms of comprehensive, effective TB control strategies and actions. For the five highest burden countries that contributed more than half of new TB cases in 2016, 10-20\% of their total populations live in slum settings [2]. It remains to be seen to what extent the urban poor, and slum residents, are explicitly integrated into the End TB Strategy. Developing a slum-specific TB control strategy should be part of the UN General Assembly High-Level Meeting on TB in September 2018, if the End TB goal is to be met by 2035 or 2025, as India has called for [62]. Furthermore, to address the information gap and to identify and treat people affected by TB, the feasibility of active case finding and innovative screening and treatment programs should be explored in countries with a high proportion of the urban population living slums. SDG 3 cannot be achieved without addressing the health risks faced by people living in urban slums.

\section{Limitations}

This study compared TB within slum settings to national incidence rates, which include slum settings, and therefore may represent a conservative estimate of the actual TB risk within slum settings. Nineteen of the 22 articles reported incidence rates within slum settings while three reported prevalence measures of tuberculosis; due to the differences in reporting, the results of this study may be overestimated where prevalence is used as part of the meta-analysis calculations. Where possible and information provided, the slum population was used as the denominator; however, only the survey sample was provided in nine studies and may underestimate the true estimates of TB in the population. In addition, because slum residents rely heavily on private sector health providers, reporting of actual TB cases from these settings may be low. The actual difference in odds of having active TB is therefore likely to be even higher than what was estimated in this analysis. This review was limited to four databases and articles published in English; it is possible that further research may be available in non-English literature. Regardless of the limitations, the results of this analysis fit well with what is known about TB transmission and the environmental, progammatic, and individual level conditions that facilitate transmission of both drug-susceptible and drugresistant TB in urban slum settings.

Acknowledgements The findings and conclusions in this report are those of the authors and do not represent views of the institutions they are affiliated with. There are no conflicts of interest to report in the development of this manuscript. No funding was provided for this research.

\section{References}

1. Global tuberculosis report 2017. Geneva: World Health Organization; 2017. Licence: CC BY-NCSA 3.0 IGO.

2. The United Nations Population Division's World Urbanization Prospects: 2014 Revision. World Bank Open Data. https://data.worldbank.org/indicator/SP.URB.TOTL. IN.ZS. Accessed 5 March 2018.

3. Lönnroth K, Jaramillo E, Williams BG, Dye C, Raviglione M. Drivers of tuberculosis epidemics: the role of risk factors and social determinants. Soc Sci Med. 2009;68(12):2240-6.

4. Raviglione MC, Snider DE, Kochi A. Global epidemiology of tuberculosis: morbidity and mortality of a worldwide epidemic. JAMA. 1995;273(3):220-6. https://doi. org/10.1001/jama.1995.03520270054031.

5. United Nations Statistics Division. SDG indicators: metadata repository. https://unstats.un.org/sdgs/metadata/. Published July 17, 2017. Accessed 5 Oct 2017.

6. UN-HABITAT. The Challenge of Slums: Global Report on Human Settlements 2003. Earthscan Publications Ltd, 2003. ISBN: 1-84407-037-9. Accessed from: http://mirror. unhabitat.org/pmss/getElectronicVersion.aspx ?alt=1 \&nr $=1156$.

7. United Nations Development Programme. Overcoming barriers. New York: United Nations Development Programme; 2009. http://hdr.undp.org/sites/default/files/reports/269 /hdr_2009_en_complete.pdf

8. Riley LW, Ko AI, Unger A, Reis MG. Slum health: diseases of neglected populations. BMC Int Health Hum Rights. 2007;7(1):2. https://doi.org/10.1186/1472-698X-7-2. 
9. World Health Organization, UN-Habitat. Hidden Cities: Unmasking and Overcoming Health Inequities in Urban Settings. World Health Organization; 2010. Accessed from: http://www.who.int/kobe_centre/publications/hiddencities media/p1_who_un_habitat_hidden_cities.pdf.

10. McMichael AJ. The urban environment and health in a world of increasing globalization: issues for developing countries. Bull World Health Organ. 2000;78(9):1117-26. https://doi.org/10.1590/S0042-96862000000900007.

11. Bates I, Fenton C, Gruber J, Lalloo D, Lara AM, Squire SB, et al. Vulnerability to malaria, tuberculosis, and HIV/AIDS infection and disease. Part II: determinants operating at environmental and institutional level. Lancet Infect Dis. 2004;4(6):368-75. https://doi.org/10.1016/S1473-3099(04 )01047-3.

12. Unger A, Riley LW. Slum health: from understanding to action. PLoS Med. 2007;4(10):1561-6.

13. Lönnroth K, Uplekar M, Blanc L. Hard gains through soft contracts: productive engagement of private providers in tuberculosis control. Bull World Health Organ. 2006;84(11):876-83. https://doi.org/10.1590/S004296862006001100012 .

14. Uplekar M, Pathania V, Raviglione M. Private practitioners and public health: weak links in tuberculosis control. Lancet. 2001;358(9285):912-6. https://doi.org/10.1016/S01406736(01)06076-7.

15. Lönnroth K, Uplekar M, Arora VK, Juvekar S, Lan NT, Mwaniki D, et al. Public-private mix for DOTS implementation: what makes it work? Bull World Health Organ. 2004;82(8):580-6. https://doi.org/10.1590/S004296862004000800007.

16. Lönnroth K, Castro KG, Chakaya JM, Chauhan LS, Floyd $\mathrm{K}$, Glaziou P, et al. Tuberculosis control and elimination 2010-50: cure, care, and social development. Lancet. 2010;375(9728):1814-29. https://doi.org/10.1016/S01406736(10)60483-7.

17. World Health Organization: Sixty-seventh World Health Assembly. The End TB Strategy.; 2014. http://www.who. int/tb/strategy/End_TB_Strategy.pdf?ua=1.

18. Stop TB Partnership, UNOPS. Global plan to end TB: the paradigm shift 2016-2020; 2015. http://www.stoptb. org/assets/documents/global/plan/GlobalPlanToEndTB TheParadigmShift_2016-2020_StopTBPartnership.pdf.

19. Stop TB Partnership. Data for action for tuberculosis: key, vulnerable and underserved populations. 2017. http://www. stoptb.org/assets/documents/communities/Data\%20for\%20 Action $\% 20$ for $\% 20$ Tuberculosis $\% 20 \mathrm{Key}, \% 20$ Vulnerable $\% 20$ and $\% 20$ Underserved $\% 20$ Populations $\% 20$ Sept\%202017.pdf. Accessed 9 Mar 2018.

20. Stop TB Partnership. Key populations brief. 2015. http://stoptb.org/assets/documents/resources/publications/ acsm/KP_Urban_Spreads.pdf. Accessed 9 Mar 2018.

21. World Health Organization, UN-HABITAT. Global report on urban health equitable, healthier cities for sustainable development. 2016. p. 241. http://www.who.int/kobe centre/publications/urban-global-report/en/. Accessed 22 April 2018.

22. Higgins JPT, Green S, eds. Cochrane Handbook for Systematic Reviews of Interventions Version 5.1.0. [updated March 2011]. The Cochrane Collaboration; 2011. www. cochrane-handbook.org. Accessed 1 December 2010.
23. Koehlmoos TP, Gazi R, Hossain SS, Rashid M. Social franchising evaluations: a scoping review. London: EPPICentre, Social Science Research Unit, Institute of Education, University of London; 2011. https://eppi.ioe.ac. $\mathrm{uk} / \mathrm{cms} /$ Portals/0/PDF\%20reviews\%20 and\%20 summaries/Social\%20Franchising\%202011Koehlmoos \%20report.pdf?ver=2011-06-06-160355-757. Accessed 21 Jul 2011.

24. Petticrew M, Roberts H. Systematic reviews in the social sciences: a practical guide. Malden: Blackwell Publishing; 2006.

25. WHO. WHO global TB report. 2002-2016. http://www. who.int/tb/publications/global_report/en/. Accessed 9 December 2017 to 15 November 2018.

26. Sterne JAC, Bradburn MJ, Egger M. Meta-analysis in Stata. In: Systematic Reviews in Health Care. BMJ Publishing Group; 2008:347-369. https://doi.org/10.1002 /9780470693926.ch18.

27. Borenstein M, Hedges L, Rothstein H. Meta-analysis: fixed effect vs. Random Effects. 2007. https://www.meta-analysis. com/downloads/M-a_f_e_v_r_e_sv.pdf.

28. Sterne J. Personal Communication: Funnel plots in metaanalysis and recommendations for examining and interpreting funnel plot asymmetry in meta-analyses of randomised controlled trials. BMJ. 2011;343(jul22 1):d4002-d4002. https://doi.org/10.1136/bmj.d4002. August 2011.

29. Pappalardo BL. Influence of maternal human immunodeficiency virus (HIV) co-infection on vertical transmission of hepatitis C virus (HCV): a meta-analysis. Int J Epidemiol. 2003;32(5):727-34. https://doi.org/10.1093/ije/dyg107.

30. Huerga $H$, Mueller Y, Ferlazzo G, et al. Implementation and operational research: feasibility of using tuberculin skin test screening for initiation of 36-month isoniazid preventive therapy in HIV-infected patients in resource-constrained settings. J Acquir Immune Defic Syndr. 2016;71(4):89.

31. Gopi PG, Prasad VV, Vasantha M, Subramani R, Tholkappian AS, Sargunan D, et al. Annual risk of tuberculosis infection in Chennai city. Indian J Tuberc. 2008;55(3):157-61.

32. Middelkoop K, Bekker L-G, Myer L, Dawson R, Wood R. Rates of tuberculosis transmission to children and adolescents in a community with a high prevalence of HIV infection among adults. Clin Infect Dis. 2008;47(3):349-55. https://doi.org/10.1086/589750.

33. Akhtar S, White F, Hasan R, Rozi S, Younus M, Ahmed F, et al. Hyperendemic pulmonary tuberculosis in peri-urban areas of Karachi, Pakistan. BMC Public Health. 2007;7(1): 70. https://doi.org/10.1186/1471-2458-7-70.

34. Mendes JM, Lourenço MC, Ferreira RMC, Fonseca L de S, Saad MHF. Drug resistance in Mycobacterium tuberculosis strains isolated from sputum samples from symptomatic outpatients: complexo de Manguinhos, Rio de Janeiro, Brazil. J Bras Pneumol. 2007;33(5):579.

35. Banu S, Rahman MT, Uddin MK, et al. Epidemiology of tuberculosis in an urban slum of Dhaka City, Bangladesh. PLoS One. 2013;8(10):e77721. https://doi.org/10.1371 /journal.pone.0077721.

36. Cavalcante SC, Soares ECC, Pacheco AGF, Chaisson RE, Durovni B, Team DE. Community DOT for tuberculosis in a Brazilian favela: comparison with a clinic model. Int $J$ Tuberc Lung Dis. 2007;11(5):544-9. 
37. Fatima R, Qadeer E, Enarson DA, et al. Success of active tuberculosis case detection among high-risk groups in urban slums in Pakistan. Int J Tuberc Lung Dis. 2014;18(9):1099104. https://doi.org/10.5588/ijtld.14.0001.

38. Fatima R, Qadeer E, Yaqoob A, et al. Extending 'contact tracing' into the community within a 50-metre radius of an index tuberculosis patient using Xpert MTB/RIF in urban, Pakistan: Did it increase case detection? PLoS ONE. 2016;11(11). https://doi.org/10.1371/journal.pone.0165813.

39. Guwatudde D, Zalwango S, Kamya MR, et al. Burden of tuberculosis in Kampala, Uganda. Bull World Health Organ. 2003;81(11):799.

40. Hoseinpoor R, Karami M, Mohammadi Y, Soltanian A. Evaluation of active case finding (ACF) of tuberculosis in slums population in North of Iran. Int J Pediatr. 2017;5(5): 4867-75. https://doi.org/10.22038/ijp.2017.21977.1837.

41. Khanal S, Baral S, Shrestha P, et al. Yield of intensified tuberculosis case-finding activities using $\operatorname{Xpert}((\mathrm{R})) \mathrm{MTB} /$ RIF among risk groups in Nepal. Public Health Action. 2016;6(2):136-41. https://doi.org/10.5588/pha.16.0015.

42. Koenig SP, Rouzier V, Vilbrun SC, Morose W, Collins SE, Joseph P, et al. Tuberculosis in the aftermath of the 2010 earthquake in Haiti. Bull World Health Organ. 2015;93(7): 498-502. https://doi.org/10.2471/BLT.14.145649.

43. Lawn SD, Bekker L-G, Middelkoop K, Myer L, Wood R. Impact of HIV Infection on the Epidemiology of Tuberculosis in a Peri-Urban Community in South Africa: The Need for Age-Specific Interventions. Clin Infect Dis. 2006;42(7):1040-7. https://doi.org/10.1086/501018.

44. Lorent N, Choun K, Thai S, et al. Community-based active tuberculosis case finding in poor urban settlements of Phnom Penh, Cambodia: a feasible and effective strategy. PLoS One. 2014;9(3):e92754. https://doi.org/10.1371 /journal.pone.0092754.

45. Miller AC, Golub JE, Cavalcante SC, et al. Controlled trial of active tuberculosis case finding in a Brazilian favela. Int $J$ Tuberc Lung Dis. 2010;14(6):720-6.

46. Ogbudebe CL, Chukwu JN, Nwafor CC, et al. Reaching the underserved: Active tuberculosis case finding in urban slums in southeastern Nigeria. Int J Mycobacteriol. 2015;4(1):1824. https://doi.org/10.1016/j.ijmyco.2014.12.007.

47. Prasad BM, Satyanarayana S, Chadha SS. Lessons learnt from active tuberculosis case finding in an urban slum setting of Agra city, India. Indian J Tuberc. 2016;63(3): 199-202. https://doi.org/10.1016/j.ijtb.2016.08.006.

48. Reif LK, Rivera V, Louis B, Bertrand R, Peck M, Anglade $\mathrm{B}$, et al. Community-Based HIV and Health Testing for High-Risk Adolescents and Youth. AIDS Patient Care STDs. 2016;30(8):371-8. https://doi.org/10.1089 /apc.2016.0102.

49. Saunders MJ, Wingfield T, Tovar MA, et al. A score to predict and stratify risk of tuberculosis in adult contacts of tuberculosis index cases: A prospective derivation and external validation cohort study. Lancet Infect Dis. 2017. https://doi.org/10.1016/S1473-3099(17)30447-4.
50. Sekandi JN, Neuhauser D, Smyth K, Whalen CC. Active case finding of undetected tuberculosis among chronic coughers in a slum setting in Kampala, Uganda. Int $J$ Tuberc Lung Dis. 2009;13(4):508-13.

51. Shrivastava SR, Shrivastava PS. HIV-tuberculosis interface: A comparison of collateral prevalence of HIV and tuberculosis in an urban health centre. Ann Trop Med Public Health. 2013;6(3):290-6. https://doi.org/10.4103/17556783.120986.

52. Shrivastava SR, Shrivastava PS. Tuberculosis: active case finding survey in an urban area of India, in 2012. J Res Health Sci. 2013;13(1):19-23.

53. Tupasi TE, Radhakrishna S, Quelapio MID, et al. Tuberculosis in the urban poor settlements in the Philippines. Int J Tuberc Lung Dis. 2000;4(1):4-11.

54. Wood R, Middelkoop K, Myer L, Grant AD, Whitelaw A, Lawn SD, et al. Undiagnosed tuberculosis in a community with high HIV prevalence: implications for tuberculosis control. Am J Respir Crit Care Med. 2007;175(1):87-93. https://doi.org/10.1164/rccm.200606-759OC.

55. Bekker L-G, Wood R. The changing natural history of tuberculosis and HIV coinfection in an urban area of hyperendemicity. Clin Infect Dis. 2010;50(s3):S214. https://doi.org/10.1086/651493.

56. Chakaya JM, Meme H, Kwamanga D, Githui WA, Onyango-Ouma WO, Gicheha C, et al. Planning for PPMDOTS implementation in urban slums in Kenya: knowledge, attitude and practices of private health care providers in Kibera slum, Nairobi. Int J Tuberc Lung Dis. 2005;9(4): 403-8.

57. Suganthi P, Chadha VK, Ahmed J, Umadevi G, Kumar P, Srivastava R, et al. Health seeking and knowledge about tuberculosis among persons with pulmonary symptoms and tuberculosis cases in Bangalore slums. Int J Tuberc Lung Dis. 2008;12(11):1268-73.

58. David AM, Mercado SP, Becker D, Edmundo K, Mugisha F. The prevention and control of HIV/AIDS, TB and vectorborne diseases in informal settlements: challenges, opportunities and insights. J Urban Health Bull. 2007;84(3 Suppl): i65.

59. Ongugo K, Hall J, Attia J. Implementing tuberculosis control in Papua New Guinea: a clash of culture and science? J Community Health. 2011;36(3):423-30. https://doi. org/10.1007/s10900-010-9324-8.

60. Singh MM, Bano T, Pagare D, Sharma N, Devi R, Mehra M. Knowledge and attitude towards tuberculosis in a slum community of Delhi. J Commun Dis. 2002;34(3):203-14.

61. Raguenaud M, Zachariah R, Massaquoi M, Ombeka V, Ritter H, Chakaya JM. High adherence to anti-tuberculosis treatment among patients attending a hospital and slum health centre in Nairobi, Kenya. Glob Public Health. 2008;3(4):433-9. https://doi.org/10.1080/17441690802063205.

62. Ditiu L, Sands P. A historic chance to end tuberculosis. http://news.trust.org/item/20180313104821-951nr/. Published March 13, 2018. Accessed 14 Mar 2018. 